\begin{tabular}{l|l}
\hline & $\begin{array}{r}\text { SISTEMA } \\
\text { ELETRONNICO } \\
\text { DE REVISTAS } \\
\text { SER I UFPR }\end{array}$ \\
unw.ser.ufpr.br \\
\end{tabular}

\title{
As dimensões da sustentabilidade dos Sistemas Agroflorestais - SAFs: um estudo no Projeto de Reflorestamento Consorciado e Adensado - RECA, Ponta do Abunã - RO
}

\section{The Dimensions of Agroforestry Systems Sustainability - SAFs: A study on the Joint Venture and Dense Reforestation Project - RECA, Ponta do Abunã - RO}

\author{
Ana Íris Tomás VASCONCELOS ${ }^{1}$, Editinete André da Rocha GARCIA², Cora Franklina Carmo FURTADO ${ }^{3 *}$, \\ José Ednilson de Oliveira CABRAL ${ }^{4}$ \\ ${ }^{1}$ Universidade Estadual Vale do Acaraú (UVA), Sobral, CE, Brasil. \\ ${ }^{2}$ Universidade Federal do Ceará (UFC), Fortaleza, CE, Brasil. \\ ${ }^{3}$ Universidade Estadual do Ceará (UECE), Fortaleza, CE, Brasil. \\ ${ }^{4}$ Empresa Brasileira de Pesquisa Agropecuária - Embrapa Agroindústria Tropical, Fortaleza, CE, Brasil. \\ *E-mail de contato: cora.franklina@uece.br
}

Artigo recebido em 29 de dezembro de 2014, versão final aceita em 6 de abril de 2016.

RESUMO: O estudo propôs verificar a contribuição do Projeto de Reflorestamento Econômico Consorciado e Adensado - RECA, que se caracteriza como um sistema agroflorestal, organizado em comunidades produtoras de pupunha, castanha do Brasil, cupuaçu e outros produtos da floresta na perspectiva de quatro dimensões da sustentabilidade: institucional, econômica, ambiental e social. A metodologia adotada foi de análise de conteúdo por meio da avaliação de notas de campo do projeto, as quais foram analisadas por meio do software AtlasTi, 6.0, à luz das categorias que foram estabelecidas e apresentadas, considerando essas quatro dimensões. Após análise, os resultados apontaram que houve: melhoria de renda dos associados, amadurecimento da comunidade para o trabalho coletivo, práticas voltadas à sustentabilidade, diferenças de performance entre os participantes do grupo, assim como o desenvolvimento de produtos e subprodutos. Após observar impactos positivos no aspecto da sustentabilidade, sugere-se a realização de estudos adicionais para avaliar a dimensão institucional no projeto.

Palavras-chave: sustentabilidade; sistemas agroflorestais; triple bottom line.

ABSTRACT: The study aimed to determine the contribution of Joint Venture for Economic Reforestation (Reflorestamento Econômico Consorciado e Adensado, RECA), which is an agroforestry system, organized in communities which produce peach palm, Brazil nut, cupuaçu and other forest products from the perspective of four sustainability 
dimensions: institutional, economic, environmental and social. The methodology chosen, was a content analysis through the evaluation of the project field notes, which were analyzed using the software AtlasTi in the light of the categories that were established and presented, considering those four dimensions. After analyzing the results, they showed that there was: improvement in the associates incomes, maturing of the community for collective work, sustainability-oriented practices, performance differences among the group members as well as product and byproducts development. After observing positive impacts on the aspect of sustainability, the carry out of additional studies to assess the institutional dimension in the project was suggested.

Keywords: sustainability; agroforestry systems; triple bottom line.

\section{Introdução}

Um dos maiores desafios enfrentados pelo homem é o de promover o desenvolvimento sem agredir a natureza. Alvo de inúmeras críticas por considerar prioritariamente o crescimento econômico, o modelo convencional de desenvolvimento tem sido questionado quanto aos seus benefícios para a sociedade e para o meio ambiente.

Conforme critica Bellen (2006, p. 116), “o modelo atual de desenvolvimento é autodestrutivo e as diversas iniciativas para modificar esse quadro não têm sido suficientemente efetivas para reverter o processo de deterioração global". Diante de tais críticas, um novo modelo de desenvolvimento tem sido proposto como forma de buscar alternativas mais responsáveis com o bem-estar humano e ambiental.

Popularizada no século XX, a partir da Conferência das Nações Unidas para o Meio Ambiente e Desenvolvimento (CNUMAD), a ideia do desenvolvimento sustentável tem se mostrado um dos movimentos sociais mais importantes deste século. Sua proposta vem ganhando ímpeto por se caracterizar como um modelo de desenvolvimento que procura conciliar as dimensões econômica, social e ambiental, respeitando os limites impostos pela natureza (Bellen, 2006).

Entre os debates sobre sustentabilidade, são comuns os itens produção de alimentos, geração de renda e conservação do meio ambiente, apontando inevitavelmente para a agricultura e suas condições de produção como o eixo básico de onde partem as demais preocupações relacionadas à sustentabilidade do nosso modo de vida e de produção (Dantas, 1994).

De modo particular, os sistemas agroflorestais - SAFs - pautam-se na ideia de sustentabilidade, já que permitem, entre outras coisas, melhor utilização da terra e da mão de obra, maior produção e produtividade, menor intensidade de manejo do ecossistema, manutenção/aumento dos níveis de biodiversidade, melhoria da fertilidade dos solos, apontando, com isso, para a melhoria das condições de inserção no mercado ou maior autonomia dos agricultores envolvidos (Raintree \& Warner, 1986).

Corroborando o exposto, Oliveira et al. (2008) apontam os sistemas agroflorestais como parte das diretrizes centrais de desenvolvimento rural sustentável, tendo em vista suas vantagens socioeconômicas e ambientais, como diminuição dos riscos econômicos assumidos pelos agricultores e restauração de áreas degradadas ambientalmente. Um exemplo é o caso do desenvolvimento com os SAFs que ocorreram no município de Esperantina, no Piauí, na comunidade Veredas do Anacleto em 2006, que consistiram em nove anos com o manejo sustentável do solo. A gestão dos SAFs orienta que o solo seja manejado com os próprios nutrientes, ao invés das queimadas que se aplicam no sistema 
convencional. Na Amazônia, Castro et al. (2009) relatam os casos dos SAFs na localidade de Costa da Terra Nova, formados por três subsistemas importantes para a comunidade local, os quais são divididos em roça, quintal e lago. Geralmente o solo é inundado com as enchentes e a população empreende estratégias de sobrevivência reversando entre as plantações na roça ou no quintal. Castro et al. (2009) também estudaram as categorias silviagrícolas, silvipastoris e agrossilvipastoris na mesma localidade.

Diante dos indícios apresentados, parte-se do seguinte questionamento: como o sistema agroflorestal contribui para a sustentabilidade? Para subsidiar a resposta a este questionamento, o presente estudo propõe verificar a contribuição do Projeto de Reflorestamento Consorciado e Adensado-RECA, que se caracteriza como um sistema agroflorestal, em cada uma das dimensões da sustentabilidade.

A fim de cumprir os objetivos traçados, este estudo é estruturado em seis seções. Além da introdução, a segunda seção aborda os conceitos teóricos que embasam o estudo e está dividida em três subseções: 2.1 - Conceito de sustentabilidade e de suas dimensões; 2.2 - A interlocução entre sistema agroflorestal e sustentabilidade; e a subseção 2.3, que contextualiza o Projeto de Reflorestamento Consorciado e Adensado - RECA; a terceira seção descreve os procedimentos metodológicos, como população pesquisada, instrumento de pesquisa e procedimentos de análise. Na quarta seção apresentam-se os resultados da pesquisa, com a análise e discussões dos dados, e na quinta seção são realizadas as conclusões que responderam à problemática e descreveram o alcance dos objetivos.

\section{Revisão bibliográfica}

\subsection{Conceito e dimensões da sustentabilidade}

Durante o século XX, o impacto do crescimento populacional e econômico sobre o meio ambiente foi enorme. Em 1804, a população mundial atingiu um bilhão de pessoas. Nas décadas seguintes, paralelamente à difusão do modo de produção e consumo industrial, o volume da população mundial cresceu, atingindo mais de seis bilhões de pessoas no ano 2000 (Maddison, 2005).

Como reflexo, atualmente não resta dúvida que as consequências da atividade econômica humana, tal como se deu historicamente, tiveram um efeito negativo sobre o ambiente natural, provocando alterações significativas no clima e nas condições de vida do planeta. Conforme afirma Lovelock (2006, p. 4), “o mundo já ultrapassou o ponto de não retorno quanto às mudanças climáticas e a civilização como a conhecemos dificilmente irá sobreviver".

Diante deste cenário, o termo sustentabilidade foi introduzido para fornecer um meio para lidar com os problemas relacionados com a deterioração da relação entre a nossa ecologia global e o desenvolvimento econômico em curso (Chiesa et al., 1999). A sustentabilidade aponta, portanto, maneiras em que um desenvolvimento econômico poderia ser realizado, tendo supostos limites ambientais em consideração (Meadows et al., 1972).

Para Sachs (2009, p. 52), o crescimento econômico é necessário, mas deve ser "socialmente receptivo e implementado por métodos favoráveis ao meio ambiente, em vez de favorecer a incorporação predatória do capital da natureza ao PIB". Reflexões como esta, que começam a surgir a partir 
da década de 1970, contribuíram para o surgimento do conceito de desenvolvimento sustentável. Sua ideia central foi definida pela Comissão Mundial sobre Meio Ambiente e Desenvolvimento, por intermédio do Relatório Brundtland (1991, p. 8), como "desenvolvimento que satisfaz as necessidades do presente sem comprometer a capacidade das gerações futuras de suprir suas próprias necessidades".

Desde o surgimento do termo desenvolvimento sustentável, muitos são os conceitos que lhe são atribuídos. Deponti (2001, p. 30) afirma que, "em pouco mais de uma década, surgem centenas de conceitos e várias correntes postulando formas e critérios diferentes de desenvolvimento sustentável". Embora reconhecendo que não haja consenso sobre muitas questões importantes acerca do desenvolvimento sustentável, Barbieri \& Cajazeira (2009, p. 69) intitulam o desenvolvimento sustentável como o "maior movimento global da atualidade".

Sobre as divergências que permeiam o termo, Almeida (2010, p. 347) esclarece que, apesar dos defensores do desenvolvimento sustentável compartilharem a preocupação com os destinos da Terra, ainda divergem quanto à ênfase sobre: o que deve ser sustentado, o que precisa ser desenvolvido, os tipos de ligação que deveriam existir entre o que deve ser sustentado e o que precisa ser desenvolvido, bem como a extensão do futuro. Para o mencionado autor, dentre os aspectos a serem mantidos, estão inclusos "a natureza (biodiversidade de espécies e ecossistemas), os sistemas de suporte à vida (recursos naturais, ambiente e serviços do ecossistema) e a comunidade (atenção às espécies culturais, não só às biológicas)". Entre os aspectos a desenvolver, cita as pessoas, a economia e a sociedade, esta enfatizando o bem-estar e a segurança de estados, regiões e instituições.

Diante do exposto, vale salientar que, para qualquer corrente de pensamento, o desenvolvi- mento sustentável contempla as dimensões econômica, social e ambiental e seus vínculos com outras dimensões mais específicas, como: política, institucional, cultural, democrática, ética, tecnológica, entre outras (Moura, 2002). Assim, dentre as diversas abordagens em torno da sustentabilidade, uma das mais conhecidas é a que considera que a sustentabilidade é amparada por três pilares: (i) econômico; (ii) ambiental; e (iii) social, os quais são frequentemente referenciados como Triple Bottom Line (TBL) (Nobre Filho et al., 2006; Lee \& Kim, 2009), conforme apresentado na Figura 1.

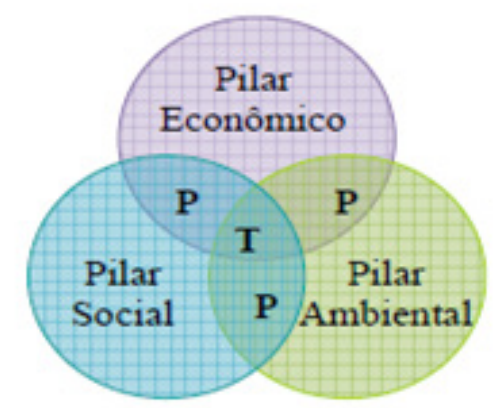

\section{P: Integração Parcial T: Integração Total}

FIGURA 1 - Os pilares da sustentabilidade. FONTE: Adaptado de Lozano (2008, p. 139).

\section{O framework Triple Bottom Line traz a pro-} posta de que haja uma integração entre os pilares que compõem a sustentabilidade, de forma a serem sempre considerados em seu conjunto (Lozano, 2008). A dimensão econômica da sustentabilidade considera o mundo referente aos aspectos de estoque e fluxo de capital. Todavia, esta visão não se restringe ao capital monetário ou econômico, mas está aberta a considerar outros tipos de capitais identificados em ambiental ou natural, capital humano e capital social, abrangendo, além da economia ambiental e questões gerenciais de cunho 
ambiental, o desenvolvimento da economia e da sociedade (Rogers et al., 2008).

O pilar ambiental da sustentabilidade engloba a preservação dos recursos naturais na produção de recursos renováveis e sua limitação na produção de recursos não renováveis, tendo como base a capacidade de autodepuração dos ecossistemas naturais e a redução do volume de resíduos e poluição, por meio da conservação de energia e da reciclagem (Elkington, 2001; Martins \& Oliveira, 2005).

Por fim, completando o tripé da sustentabilidade, a dimensão social refere-se ao controle dos efeitos causados pelas desigualdades sociais, traduzidos em contradições e disputas causadoras de patologias sociais (Machado \& Fenzl, 2001). Envolve, portanto, trabalho, rendimento, saúde, educação, habitação e segurança das pessoas (IBGE, 2004).

Acredita-se que a definição acima explicita a interação entre a dimensão social e o conceito de empoderamento, tendo em vista que os indicadores sociais têm o potencial de proporcionar um ambiente favorável para a construção da autonomia dos indivíduos.

Perkins \& Zimmerman (1995, p. 1) definem empoderamento como "um construto que liga forças e competências individuais, sistemas naturais de ajuda e comportamentos proativos com políticas e mudanças sociais". Trata-se da constituição de organizações e comunidades responsáveis, mediante um processo no qual os indivíduos que as compõem obtêm controle sobre suas vidas e participam democraticamente no cotidiano de diferentes arranjos coletivos e compreendem criticamente seu ambiente (Antunes, 2002).

Aliado à dimensão social da sustentabilidade, o empoderamento é colocado no Brasil na visão de Freire (1986), que considera "a libertação um ato social" (Freire, 1986; Baquero, 2012, p. 180).
Freire apud De Castro Valoura (2010) considera como empoderada a pessoa ou grupo que realiza por si mesma as mudanças e ações que a levam a evoluir e se fortalecer. Freire (1986, p. 135) apud Baquero (2012, p. 180-181) traz citação pertinente acerca do empoderamento:

\begin{abstract}
Mesmo quando você se sente, individualmente, mais livre, se esse sentimento não é um sentimento social, se você não é capaz de usar sua liberdade recente para ajudar os outros a se libertarem através da transformação da sociedade, então você só está exercitando uma atitude individualista no sentido do empowerment ou da liberdade.
\end{abstract}

Considerando o potencial da contribuição dos sistemas agroflorestais para a sustentabilidade, a próxima subseção discorre sobre a interlocução entre os sistemas agroflorestais e a sustentabilidade.

\subsection{Interlocução entre sistemas agroflorestais e sustentabilidade}

Sistemas Agroflorestais são sistemas de uso de terra e tecnologias onde espécies perenes são deliberadamente usadas nas mesmas unidades de manejo juntamente com cultivos agrícolas temporários e/ ou animais em alguma forma de arranjo espacial ou sequência temporal (Lundgren \& Raintree, 1982; Nair, 1990).

Almeida, Müller e Sena-Gomes (2002) afirmam que os Sistemas Agroflorestais (SAFs) são reconhecidamente modelos de exploração de solos que mais se aproximam ecologicamente da floresta natural e, por isso, considerados como importante alternativa de uso sustentado do ecossistema tropical úmido.

De acordo com a Embrapa (2006), os sistemas agroflorestais podem ser subdivididos em: (a) 
Sistemas agrossilviculturais - quando combinam árvores com cultivos agrícolas anuais; (b) Sistemas agrossilvipastoris - nos casos onde há a combinação de árvores com cultivos agrícolas e animais; e (c) Sistemas silvipastoris - combinam árvores e pastagem (animais).

Dantas (1994) caracteriza os sistemas agroflorestais da seguinte forma: (a) são compostos por, no mínimo, duas espécies, sendo pelo menos uma perene, e (b) são sistemas que envolvem interações ecológicas e econômicas, gerando benefícios variados em ciclos sempre superiores a um ano.

Analisando com mais detalhe as vantagens associadas aos sistemas agroflorestais, é possível identificar com mais clareza sua relação com os pilares da sustentabilidade. Com relação à dimensão econômica, a diversidade de espécies encontrada nos sistemas agroflorestais permite a obtenção de um número maior de produtos e/ou serviços a partir de uma mesma unidade de área, tanto para a subsistência da família quanto para o mercado (Kato et al., 2012).

Raintree \& Warner (1986) ainda afirmam que os sistemas agroflorestais geralmente necessitam de baixo capital para sua manutenção quando comparados aos sistemas de monocultivo. Como reflexo, Nair (1990) propõe que tal sistema proporciona maior eficiência na utilização de mão de obra versus o uso da terra.

Para a dimensão ambiental, a Embrapa (2008) destaca que o consórcio de espécies de diferentes exigências em luz, água e nutrientes possibilita o uso mais eficiente desses recursos. Estudos de Araújo et al. (2005) apud Embrapa (2008) mostraram que sistemas de manejo alternativos, como o uso da adubação verde, resultaram em aumento considerável dos nutrientes presentes no solo e nas quantidades de carbono total e nitrogênio total se comparadas com ambiente nativo do cerrado. Além dessa observação, esses estudos apontaram que os sistemas convencionais, os quais adotam o corte e a queimada, apresentaram em curto prazo valores maiores de nutrientes em relação aos alternativos, entretanto, no médio e longo prazo esgotaram a matéria orgânica do solo e reduziram a qualidade para o cultivo (Embrapa, 2008).

Enfim, a relação do sistema agroflorestal com a dimensão social se dá quando este contribui com a qualidade de vida do pequeno agricultor (Anderson et al., 1985) e a área com sistema agroflorestal pode ser usada permanentemente, minimizando a necessidade de derruba e queima de novas áreas e aumentando as chances de fixação do homem no campo (Embrapa, 2008).

Com base no exposto, percebe-se por que os sistemas agroflorestais são considerados com maior potencial para a sustentabilidade quando comparados a outros sistemas de cultivo puramente agrícola ou puramente florestal. Sobre isso, Anderson et al. (1985) sintetizam que o potencial dos sistemas agroflorestais para contribuir com a qualidade de vida do pequeno agricultor e de realçar o potencial de sustentabilidade de seus sistemas produtivos cresce quando a agrofloresta está aliada com outros sistemas de produção na mesma propriedade.

Entretanto, Fernandes \& Serrão (1992) lembram que um sistema agroflorestal somente pode ser considerado sustentável quando é capaz de oferecer continuamente respostas às necessidades específicas da comunidade onde se encontra, sem que ocorra a degradação dos recursos naturais dos quais o sistema depende, considerando as dinâmicas relações entre sistemas econômicos e ecológicos, em particular questões como estoques de capital natural, níveis de extração e capacidade de assimilação pelo meio ambiente de resíduos/rejeitos da atividade produtivo-econômica. 
Assim, Peneireiro (2007) afirma que para um sistema agroflorestal ser sustentável, ou seja, manter-se produtivo e que ao mesmo tempo mantenha ou melhore as condições do lugar (com relação ao solo, à água, à diversidade de vida), deve-se: (a) plantar muitos tipos de plantas, de diferentes tempos de vida; (b) combinar as plantas de forma que as que têm aproximadamente o mesmo tempo de vida possam ocupar todos os estratos, em diferentes alturas; (c) manter o solo sempre coberto com muita matéria orgânica; e (d) plantar as plantas cultivadas no espaçamento tradicional e as árvores bem juntas, de modo que possam ser selecionadas com o tempo e fiquem as mais vigorosas.

\subsection{Caso RECA}

No sentido de mudar a realidade social e ambiental de três distritos, Fortaleza do Abunã, Extrema e Nova Califórnia, que são parte da região pertencente ao município de Porto Velho, capital de Rondônia, surgiu o Projeto de Reflorestamento Econômico Consorciado e Adensado (RECA).

A ideia principal do supracitado projeto era desenvolver um sistema de floresta produtiva que fosse capaz de gerar renda e reflorestar as áreas desmatadas ao mesmo tempo. Os colonos já tinham percebido que a lavoura branca (como o cultivo do arroz, feijão e café) não se adaptava bem às condições do solo e do clima amazônico, por isso começaram a tentar cultivar plantas que já fossem adaptadas à região, como a castanheira, a pupunheira e o cupuaçuzeiro.

No início do projeto, cada família associada recebeu, a fundo perdido da entidade holandesa Cebemo, atual Bilance, 958 dólares por hectare, não podendo exceder o valor referente a três hectares. Tal dinheiro, ao invés do que ocorre em muitas as- sociações, não foi dado ao produtor, e sim repassado em forma de financiamento. Os sócios assinavam um contrato se comprometendo a devolver o dinheiro na forma de produção.

O projeto contava em 2015 com cerca de 300 famílias, estando dividido em 12 grupos: Pioneiros I, II e III, Cascalho, Baixa Verde, Mendes Junior, Eletrônica, BR, Linha 04, Linha 05, Linha 06 e Linha 12. Esses grupos têm sua formação e composição definidas geralmente com base na proximidade das propriedades dos associados, isto é, o grupo é composto por pessoas cujas propriedades localizam-se próximas umas das outras, nos chamados ramais, havendo alguns poucos casos de produtores que aderiram a determinado grupo por questões de afinidade e identificação com os demais membros do mesmo, ainda que sua propriedade seja distante.

\section{Método}

\subsection{Classificação do estudo}

O estudo foi de natureza qualitativa porque tratou de questões que não são quantificadas. De acordo com De Souza-Minayo (1994), a linha qualitativa fundamenta a linha teórica, ou seja, busca entender as questões do comportamento humano, da compreensão das vivências sociais. "Em suas diferentes manifestações, como na fenomenologia, na Etnometodologia, no Interacionismo Simbólico, o significado é o conceito central de investigação" (De Souza-Minayo, 1994). O objetivo da utilização de uma abordagem qualitativa foi apreender os significados do objeto estudado e entender os efeitos gerados pelo Projeto de Reflorestamento Econômico Consorciado e Adensado (RECA) nas dimensões da sustentabilidade. De acordo com 
Flick (2009), a importância da mobilidade da pesquisa qualitativa influencia tanto em termos acadêmicos quanto empíricos para solucionar problemas. Dessa forma, foram traçadas, por meio da Teoria do Triple Bottom Line e da dimensão institucional, categorias para a avaliação dos resultados observados a partir do objeto em estudo.

\subsection{Método de estudo de caso}

Tomando por base Merrian (1988), o estudo de caso qualitativo poderá representar uma investigação intensiva, a descrição holística e a análise de um único exemplo, um único fenômeno social ou unidade. Estudo de caso conforme Yin (1994) é uma forma empírica que investiga um fenômeno contemporâneo dentro do contexto de vida real. Para Godoy (1995), o estudo de caso toma por objeto a análise de uma unidade. Diante dessas proposições de estudo de caso, utilizou-se como unidade de estudo a análise do projeto RECA, devido a sua importância para as famílias beneficiadas e a proposta de um exemplo que contribui para alcance de impactos em outras comunidades.

\subsection{Plano amostral}

Para os pesquisadores qualitativos, o processo de pesquisa qualitativa é o reflexo de um diálogo entre os investigadores e os respectivos sujeitos, em que os investigadores estabelecem estratégias que possibilitam considerar as vivências dos pontos de vista dos sujeitos da pesquisa (Bogdan \& Biklen, 1994). Foram entrevistados 20 integrantes do RECA, nos diferentes grupos, bem como os integrantes da direção do projeto estudado. Utilizou-se o critério da saturação para delimitar a quantidade de entrevistas.

\subsection{Análise dos dados}

A análise dos dados foi realizada por meio da análise de conteúdo, uma vez que oferece suporte a uma análise produtiva e enriquecedora no sentido de promover uma criticidade analítica (Bardin, 2006). Tal análise foi realizada nas notas de campo de um estudo de três semanas no RECA, período no qual foram aplicadas as entrevistas. Em relação ao processo de decodificação, o projeto foi dividido em dimensões e seus relatos foram analisados.

\subsection{Tratamento dos dados}

O estudo se propôs a verificar como um sistema agroflorestal contribui para a sustentabilidade, partindo da análise da nota de campo elaborada por ocasião de visita feita ao projeto RECA. Para fins da pesquisa, a nota de campo foi analisada com o uso do software Atlas/Ti, versão 6.0, à luz das categorias demonstradas na Tabela 1, desenvolvidas a partir das dimensões propostas no modelo do triple bottom line (Elkington, 2001).

O software foi útil para identificar elementos na nota de campo que pudessem estar associados às categorias estabelecidas na pesquisa conforme apresentadas na Tabela $1 \mathrm{e}$, consequentemente, ligados a cada dimensão. Além disso, o software permitiu a visualização das ligações entre os diversos elementos na nota de campo na forma de teias, conforme demonstrado na Figura 2. Nesta figura, se observa que a dimensão é considerada o elemento principal, que se liga a uma categoria, que se liga a uma frase no texto analisado. Em relação aos dados apresentados entre chaves, tem-se que o primeiro número representa a quantidade de trechos vinculados diretamente àquele elemento. $\mathrm{O}$ segundo número representa $\mathrm{a}$ quantidade de ligações entre os elementos. 
Na Figura 2, "Dimensão" é o elemento superior da teia e não existe nenhum trecho do documento analisado ligado diretamente ao mesmo. Categorias são parte desse elemento e estão representadas em dois trechos do documento, que foi apresentado na teia.

As dimensões e categorias apresentadas na Tabela 1 identificam que aspectos de um projeto da natureza do projeto RECA contribuem para as dimensões econômica, social e ambiental.

$\mathrm{Na}$ sequência, apresentam-se as interações entre as três dimensões, uma vez que, ao analisar as notas de campo, existiram evidências de que determinadas práticas teriam uma tripla dimensão, justamente o que se buscou responder. Por fim, observou-se uma dimensão que emergiu das análises - a Dimensão Institucional, já prevista pela ONU como uma dimensão importante para a sustentabilidade.

\section{Análise e discussão dos resultados}

\subsection{Dimensão econômica}

A dimensão econômica da sustentabilidade foi evidenciada nas notas de campos, a partir dos trechos do relatório que identificavam as diversas categorias relativas a esta dimensão, conforme a Figura 3.

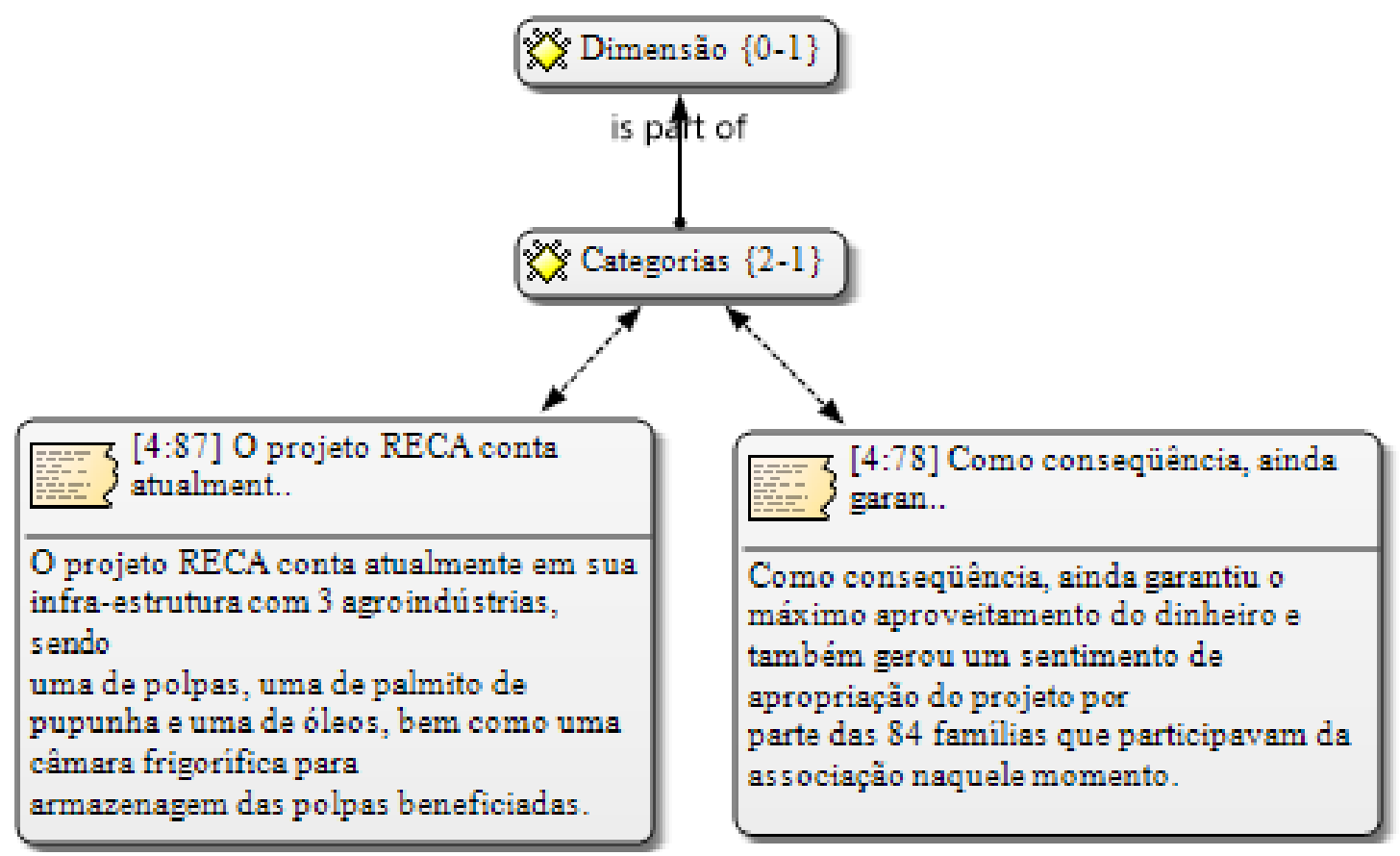

FIGURA 2 - Modelo de teia criada no Atlas/Ti. 
TABELA 1 - Categorias de análises - projeto Agroflorestal RECA (2009).

\begin{tabular}{|c|c|}
\hline Dimensão & Categorias \\
\hline \multirow{12}{*}{ 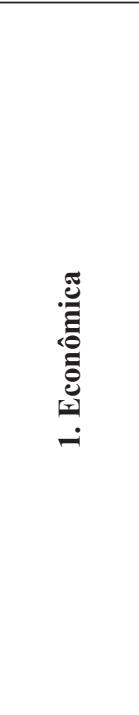 } & 1.1. DIVESP: Diversidade de espécies (possibilita maior número de produtos). \\
\hline & $\begin{array}{l}\text { 1.2. NUMPRODSFAMILIA: Obtenção de um número maior de produtos e/ou serviços a partir da mesma área } \\
\text { para subsistência da família. }\end{array}$ \\
\hline & $\begin{array}{l}\text { 1.3. NUMPRODSMERCADO: Obtenção de um número maior de produtos e/ou serviços a partir da mesma } \\
\text { área para subsistência do mercado. }\end{array}$ \\
\hline & 1.4. CAPITAL: Capital empregado. \\
\hline & 1.5. EFICIENCIA: Melhor eficiência na utilização de mão de obra versus uso da terra. \\
\hline & 1.6. NECCOMUN: Oferece resposta à necessidade da comunidade. \\
\hline & 1.7. UNIONSISTEM: Alia diversos sistemas de produção na mesma propriedade. \\
\hline & 1.8. ARRANJO: Plantar muitos tipos de plantas, de diferentes tempos de vida. \\
\hline & $\begin{array}{l}\text { 1.9. COMBPLANTAS: Combinar as plantas de forma que as que têm aproximadamente o mesmo tempo de } \\
\text { vida possam ocupar todos os estratos, em diferentes alturas. }\end{array}$ \\
\hline & 1.10. MATORGAN: Manter o solo sempre coberto com muita matéria orgânica. \\
\hline & $\begin{array}{l}\text { 1.11. MODOPLANTIO: Plantar as plantas cultivadas no espaçamento tradicional e as árvores bem juntas, de } \\
\text { modo que possam ser selecionadas com o tempo e fiquem as mais vigorosas. }\end{array}$ \\
\hline & 1.12. DISRED: Pouca diferença na distribuição de renda. \\
\hline \multirow{12}{*}{ 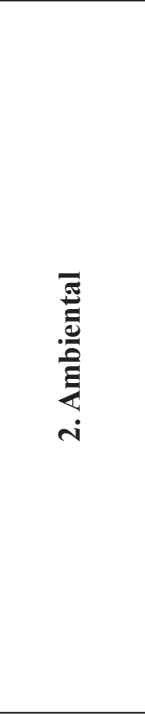 } & $\begin{array}{l}\text { 2.1. EFICIENCIAREC: Diversidade a partir de consórcio de espécies - uso eficiente de recursos (luz, água e } \\
\text { nutrientes). }\end{array}$ \\
\hline & 2.2. FASEDESENV: Fase de desenvolvimento do sistema. \\
\hline & 2.3. UNIONSISTEM: Alia diversos sistemas de produção na mesma propriedade. \\
\hline & 2.4. CAPNATURAL: Considera questões ambientais - estoque de capital natural. \\
\hline & 2.5. NIVEXTRAÇÃO: Considera questões ambientais - níveis de extração. \\
\hline & $\begin{array}{l}\text { 2.6. CAPACIDADERESIDUOS: Considera questões ambientais- capacidade de assimilação pelo meio am- } \\
\text { biente de resíduos/rejeitos da atividade produtivo-econômica. }\end{array}$ \\
\hline & 2.7. ARRANJO: Plantar muitos tipos de plantas de diferentes tempos de vida. \\
\hline & 2.8. MATORGAN: Manter o solo sempre coberto com muita matéria orgânica. \\
\hline & $\begin{array}{l}\text { 2.9. MODPLANTIO: Plantar as plantas cultivadas no espaçamento tradicional e as árvores bem juntas, de } \\
\text { modo que possam ser selecionadas com o tempo e fiquem as mais vigorosas. }\end{array}$ \\
\hline & 2.10. NATIVA: Uso da floresta em plantas nativas. \\
\hline & 2.11. MINIMQUEIMA: Uso permanente minimizando a necessidade de derruba e queima de novas áreas. \\
\hline & $\begin{array}{l}\text { 2.12. COMPLANTAS: Combinar as plantas de forma que as que têm aproximadamente o mesmo tempo de } \\
\text { vida possam ocupar todos os estratos, em diferentes alturas. }\end{array}$ \\
\hline \multirow{5}{*}{$\begin{array}{l}\bar{\pi} \\
\dot{\pi} \\
\dot{D} \\
\dot{n} \\
\dot{m}\end{array}$} & 3.1. FIXCAMP: Fixação do homem no campo. \\
\hline & 3.2. QUALILIFE: Contribuição para a qualidade de vida do pequeno agricultor. \\
\hline & 3.3. QUALICOMUNID: Oferece respostas às necessidades da comunidade. \\
\hline & 3.4. EMPODERAMENTO: Relaciona-se com as interações sociais em benefícios do grupo. \\
\hline & 3.5. DISRED: Pouca diferença na distribuição de renda. \\
\hline
\end{tabular}




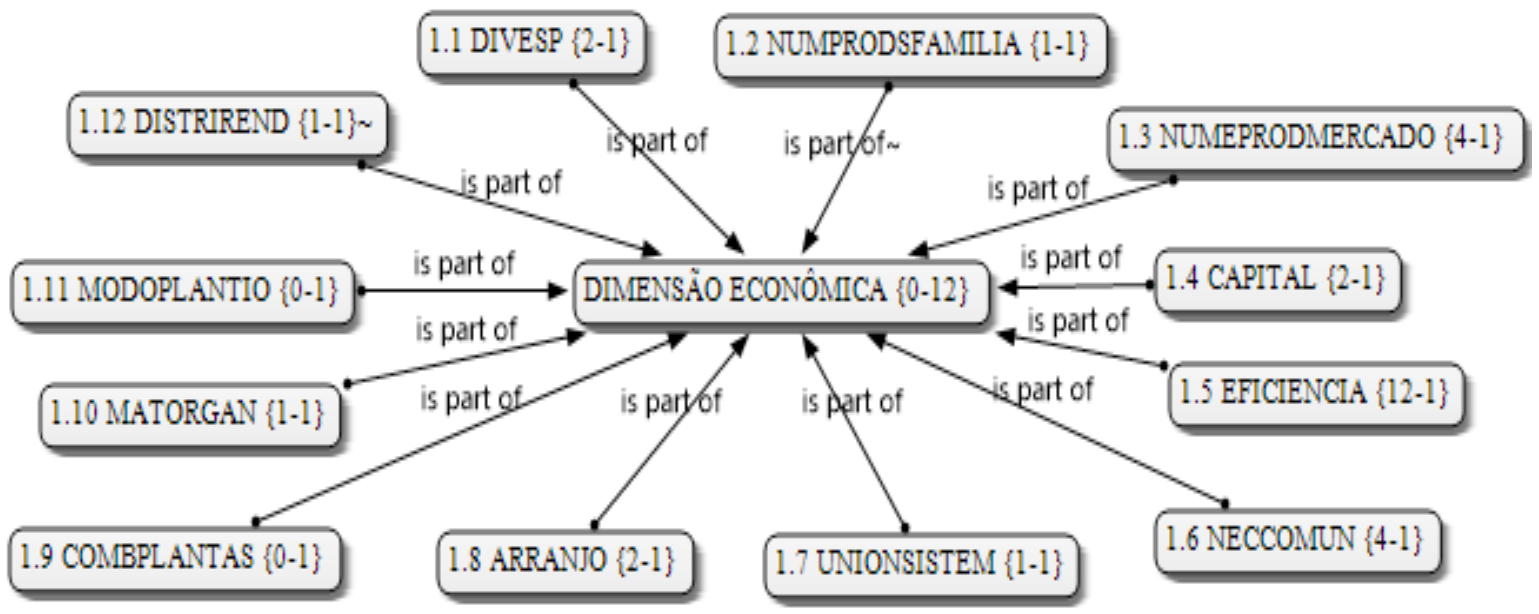

FIGURA 3 - Dimensão Econômica da Sustentabilidade do projeto RECA.

$\mathrm{Na}$ dimensão econômica ficaram evidenciados, de forma bastante acentuada, 12 trechos que são atribuídos à categoria 1.5 EFICIENCIA (Figura 4).

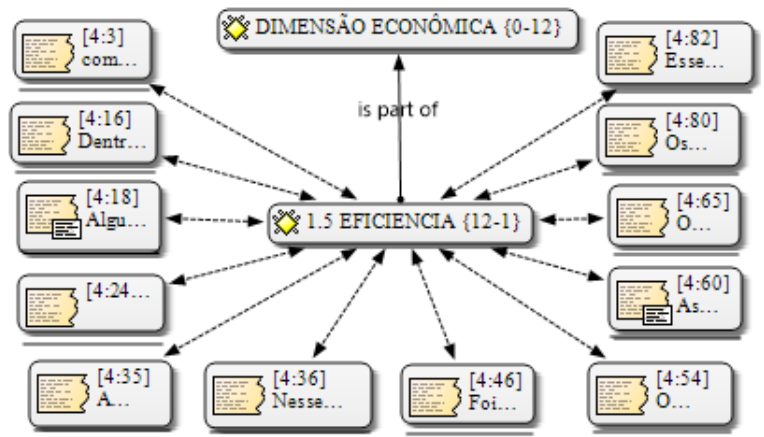

FIGURA 4 - Representação dos trechos categoria 1.5 EFICIÊNCIA.

Conforme a Tabela 1, a categoria eficiência se relaciona com a melhor relação entre utilização de mão de obra versus uso da terra. As práticas evidenciadas que caracterizam esta categoria são mostradas na Tabela 2.
TABELA2 - Categoria eficiência.

- Utilização de culturas adaptadas à região;

- Cada grupo conta com um técnico responsável, que geralmente também é um associado que se faz presente nas diversas atividades do grupo, sendo responsável pelo aprimoramento e aumento de produtividade por meio do acompanhamento do manejo das áreas como adubação, compostagem, controle de pragas e melhoria dos processos de cada área;

- Organização e capacitação das famílias;

- Utilização de mão de obra da própria comunidade formada nas escolas de famílias agrícolas (EFA), com a utilização do sistema de Pedagogia de Alternância;

- Utilização da mão de obra feminina;

- Contratação das mesmas pessoas como mão de obra temporária entre os anos, a fim de garantir o conhecimento profundo do processo de beneficiamento;

- Utilização de máquinas;

- Alia a produção agrossilvícola à conservação da floresta com a prática de florestas produtivas;

- Realização de trabalhos em conjunto, beneficiando todos os integrantes;

- Utilização da lavoura branca e da pecuária para subsistência.

Nesta categoria verifica-se, no entanto, que a organização da comunidade não se dá de forma 
homogênea, uma vez que as notas de campo evidenciam que alguns grupos conseguem responder positivamente ao sistema associativista e outros grupos enfrentam problemas internos, refletindo assim na eficiência de tais grupos. Isto se verifica no seguinte trecho da nota de campo:

\begin{abstract}
Alguns grupos apresentam diferenças com relação aos demais em diversos aspectos. Por exemplo, existem grupos onde é notável o grau de interação entre os membros, criando fortes vínculos afetivos e até mesmo familiares, enquanto outros grupos não estabeleceram esse relacionamento interpessoal. Há ainda grupos que demonstram um sentimento comunitário forte, preocupando-se não apenas consigo e sua propriedade, mas com o desenvolvimento do RECA. Por meio da observação dos assuntos levantados nas reuniões dos grupos, pode-se perceber essas pequenas diferenças, que muitas vezes parecem fazer com que determinados grupos se desenvolvam mais social e economicamente e/ou tenham uma maior visibilidade interna em relação aos outros.
\end{abstract}

Uma forma de beneficiar a comunidade está evidenciada no impacto econômico proporcionado pelo RECA, já que os recursos obtidos pela comercialização dos seus produtos geram sustento não só para as famílias dos associados. O seguinte trecho, extraído da nota de campo, revela este impacto econômico:

O RECA impacta diretamente mais de 300 famílias, porém, se contarmos os beneficiados indiretamente, o número se torna muito maior. Os recursos obtidos pela comercialização geram sustento para as famílias dos associados, e esse dinheiro automaticamente circula no comércio de Nova Califórnia e esquenta a economia local. Farmácias, padarias, lojas de construção; uma parte significante dos negócios do distrito é reflexo econômico do trabalho gerado no projeto RECA.

Além da intermediação da venda da produção, outra forma de beneficiar a comunidade se relaciona à contratação de diaristas, conforme se apresenta no trecho da nota de campo.
Todas as agroindústrias e, muitas vezes, os próprios sócios utilizam mão de obra temporária durante a safra para conseguir colher e beneficiar a produção. Esses diaristas durante os 6 ou 7 meses em que são contratados conseguem complementar suas rendas o que, por consequência, também desenvolve a atividade comercial.

Apesar destes benefícios trazidos para a comunidade, identificados nesta categoria, verificaram-se dois aspectos negativos que impactam fortemente na dimensão econômica do projeto. Estes se referem às condições precárias para escoamento da produção da comunidade e, como consequência, o alto custo do frete pago para aquisição de embalagens diretamente de indústrias de São Paulo, como se infere pelos trechos da nota de campo.

A dificuldade de acesso, segundo Sergio Lopes, inibe o setor produtivo no Acre e faz com que o RECA, por exemplo, prefira comprar potes de vidro para o palmito em São Paulo (devido à qualidade) e tenha que, por isso, assumir o aumento do custo de produção e a maior dependência em relação às estradas.

Apesar das dificuldades referentes ao transporte individual, o que mais atrapalha a vida dos moradores locais e do projeto RECA são as condições dos ramais e do deslocamento de cargas.

As demais categorias podem ser evidenciadas nas seguintes práticas, conforme Tabela 3 , que apresenta a categoria capital:

Em relação à categoria 1.12 DISTRIREND, verifica-se uma realidade preocupante que se relaciona com a distribuição de renda, já que foram identificados produtores que ganham de 3 a 100 mil reais por ano, de acordo com relatos dos entrevistados. Isto se infere do trecho a seguir destacado:

[...] há produtores que ganham de 3 a 100 mil reais por ano. A razão para esta variação é diversa; segundo os sócios entrevistados, os motivos mais ressaltados são: as particularidades de cada indivíduo, a distância do seu 
TABELA 3 - Categoria capital.

- Contrapartida do capital investido com produção [1.4 CAPITAL];

- Utilização do sistema de consórcio como cultivos agrossilvícolas como a pupunha (Bactris gasipaes), o cupuaçu (Theobroma grandiflorum) e a castanha-do-Brasil (Bertholletia excelsa H.B.K.) nos chamados SAF's (Sistemas Agroflorestais) [1.1 DIVESP] [1.3 NUMEPRODMERCADO] [1.8 ARRANJO];

- Extração e transformação em diversos produtos e subprodutos (beneficiamento de polpas, palmito de pupunha e óleos de cupuaçu, castanha do Brasil e andiroba para venda para indústria de cosméticos) [1.1 DIVESP] [1.3 NUMEPRODMERCADO] [1.2 NUMPRODSFAMILIA];

- Ao final da produção, com base nas vendas, o produtor recebe pelo fruto, pelo caroço do fruto sadio e pelo caroço do fruto estragado que é aproveitado na agroindústria de óleos [1.3 NUMEPRODMERCADO];

- Preocupação em aliar a produção agrossilvícola à conservação da floresta [1.10 MATORGAN];

- Plantação de diferentes árvores próximas, ou seja, consorciadas, como na floresta, para manter a fertilidade do solo [1.8 ARRANJO];

- Implantação de agroindústria [1.3 NUMEPRODMERCADO].

lote à sede do RECA, o tipo do solo da propriedade, a escolha da produção e organização do grupo ao qual cada associado faz parte. Para conseguir contornar essas diferenças, a associação precisa atuar e apoiar cada grupo de maneira particularizada, de acordo com cada necessidade. Um ponto que parece ser chave nessa estabilidade econômica do grupo é a união entre seus produtores e, por conseguinte, ações que promovam esse intuito também devem agregar muito a vários grupos, além de diminuir a desigualdade.

A partir da codificação, verificou-se a existência de categorias concorrentes da dimensão econômica com as dimensões ambiental e social, conforme visualizado nas próximas análises.

\subsection{Dimensão ambiental}

Diversos fatores são identificados no RECA como atribuíveis à dimensão ambiental e atribuíveis às dimensões próprias de sustentabilidade esperada em um projeto agroflorestal, que emergiu do referencial teórico apresentado nesta pesquisa. O RECA é considerado um sistema agroflorestal, uma vez que é composto por mais de duas espécies e ainda envolve interações econômicas e sociais, gerando benefícios superiores a um ano (Dantas, 1994).

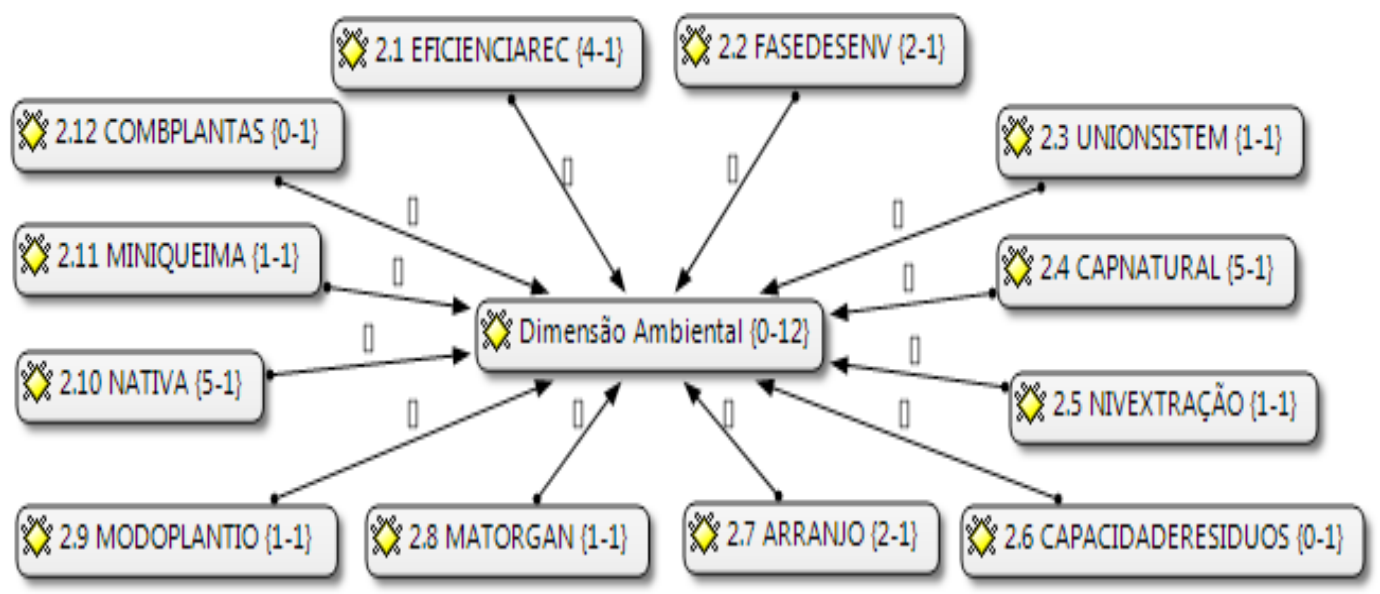

FIGURA 5 - Dimensão Ambiental da Sustentabilidade do Projeto RECA. 


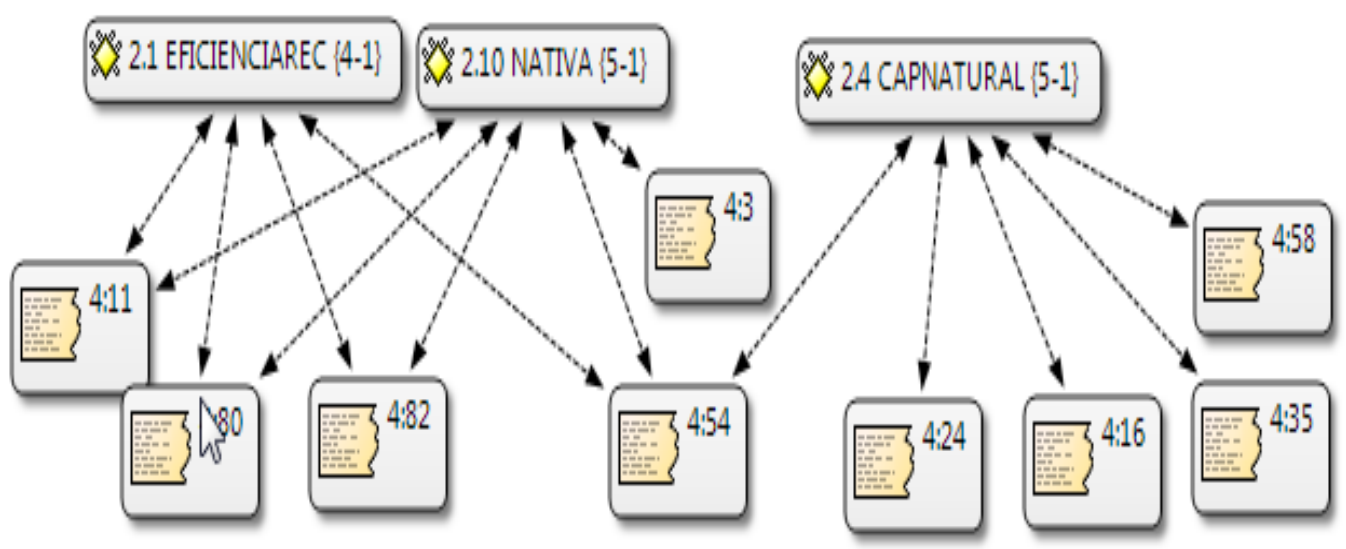

FIGURA 6 - Representação dos trechos categoria 2.1 EFICIENCIAREC 2.10 NATIVA 2.4 CAPNATURAL.

A representação sumária da análise de conteúdo (Figura 6) evidencia trechos representativos das diversas categorias atribuídas a esta dimensão, com destaque para as categorias que se relacionam à contribuição para o estoque de capital natural (2.4 CAPNATURAL), uso da floresta em plantas nativas (2.10 NATIVA) e diversidade de espécie a partir de consórcio de espécies (2.1 EFICIENCIAREC), representados em dez trechos do relatório (Figura 5).

As práticas evidenciadas que caracterizam estas categorias estão na Tabela 4.
Em síntese, verificou-se a preocupação dos entrevistados conforme descrito no seguinte trecho da nota de campo.

É visível a preocupação com a recuperação das áreas degradadas e dos mananciais. Há inclusive um projeto cujas atividades são voltadas para a recuperação dessas áreas, com o incentivo ao plantio de essências florestais nas margens de açudes, riachos, lagos, nascentes, igarapés. Essa cultura conservacionista é disseminada em todos os grupos do RECA, que enxergam a floresta como sendo um dos grandes patrimônios de que dispõem...

TABELA 4 - Categorias EFICIENCIAREC, NATIVA e CAPNATURAL

- Cultivo de plantas que já eram adaptadas à região (castanheira, pupunheira e o cupuaçuzeiro);

- Utilização do sistema de consórcio como cultivos agrossilvícolas, como a pupunha (Bactris gasipaes), o cupuaçu (Theobroma grandiflorum) e a castanha-do-Brasil (Bertholletia excelsa H.B.K.) nos chamados SAFs (Sistemas Agroflorestais);

- Utilização do modelo produtivo, organizado em Sistemas Agroflorestais;

- Busca de alternativas para ajudar na conservação e preservação do meio ambiente e sua biodiversidade;

- Formação técnica dos filhos dos produtores nas Escolas Família Agrícolas, que utiliza o sistema de Pedagogia de Alternância, no qual os alunos passam quinze dias internos na escola e quinze dias em casa, aplicando os conhecimentos adquiridos;

- Extração das amêndoas de forma artesanal;

- Recuperação de áreas degradadas e de mananciais com plantio de essências florestais nas margens de açudes, riachos, lagos, nascestes e igarapés;

- Articulação dos produtores para colocação em prática das ideias de florestas produtivas;

- Replantio constante das espécies frutíferas nativas, cultivo de lavoura branca e utilização de pastagem com fins exclusivos de subsistência. 
Com base na nota de campo, a análise que se faz é a evidência de que a utilização de tratores seria um aspecto positivo que influencia na dimensão ambiental.

Outra iniciativa do governo federal que vem dando resultados positivos são os programas de financiamento, como o de tratores e máquinas para pequenos agricultores, proporcionado pelo Banco do Brasil, que beneficiou alguns associados ao RECA.

As demais categorias são observadas nas seguintes práticas, conforme descritas na Tabela 5.

TABELA 5 - Categoria Capnatural.

- Plantio de árvores próximas umas da outras (Adensada) $[2.9$ MODOPLANTIO $] \quad[2.7 \quad$ ARRANJO $] \quad[2.2$ FASEDESENV];

- Utilização do consórcio [2.7 ARRANJO];

- Preocupação em aliar a produção agrossilvícola à conservação florestal [2.3 UNIONSISTEM] [2.5 NIVEXTRAÇÃO] [2.8 MATORGAN];

- A conservação da floresta, evidenciada no relatório, é um indício de que a comunidade abandona o desmatamento e queimadas [2.11 MINIQUEIMA];

- Recuperação das áreas degradadas com o incentivo do plantio de florestas nas margens dos rios, lagos, nascentes e igarapés [2.2 FASEDESENV].

\subsection{Dimensão social}

A análise da nota de campo sob o ponto de vista da dimensão social da sustentabilidade apresenta, como uma categoria bastante significativa, a contribuição do RECA para a qualidade de vida do pequeno agricultor, representada pela categoria 3.2 QUALILIFE, que pode ser considerada como um fator que contribui para a fixação do homem no campo, juntamente com seu empoderamento.

Como apresentado na Figura 7, foram identificadas quatro categorias, a partir da análise da nota de campo.

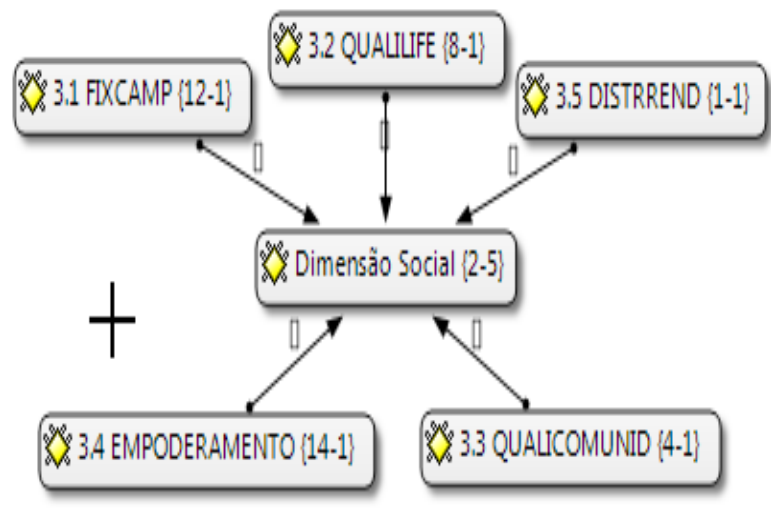

FIGURA 7 - Dimensão Social da Sustentabilidade do Projeto RECA.

As evidências desta dimensão são apresentadas em diversos trechos do relatório, como apresentado na Figura 8.

Observa-se, pelos objetivos do RECA, seu compromisso com as dimensões da sustentabilidade, já que em seu estatuto propõe: (a) fixação das famílias no campo por meio de ajuda mútua; (b) organização das famílias de pequenos agrossilvicultores em grupos para estudos, trabalhos, ajuda mútua e convivência fraterna; (c) implantação de um sistema educacional adequado à realidade rural; (d) capacitação dos associados para administrar e gerir os seus negócios e os da associação; (e) venda em comum da produção agrossilvicultural e extrativista nos mercados locais, nacionais e internacionais; (f) busca de alternativas para ajudar na conservação e preservação do meio ambiente e sua biodiversidade; (g) classificação, padronização, armazenamento, beneficiamento, industrialização e registro das marcas de seus produtos.

Os trechos destacados para análise evidenciam as seguintes situações que impactam em uma ou em algumas categorias de forma concorrente da dimensão social e são apresentadas de forma objetiva, como segue na Tabela 6 . 


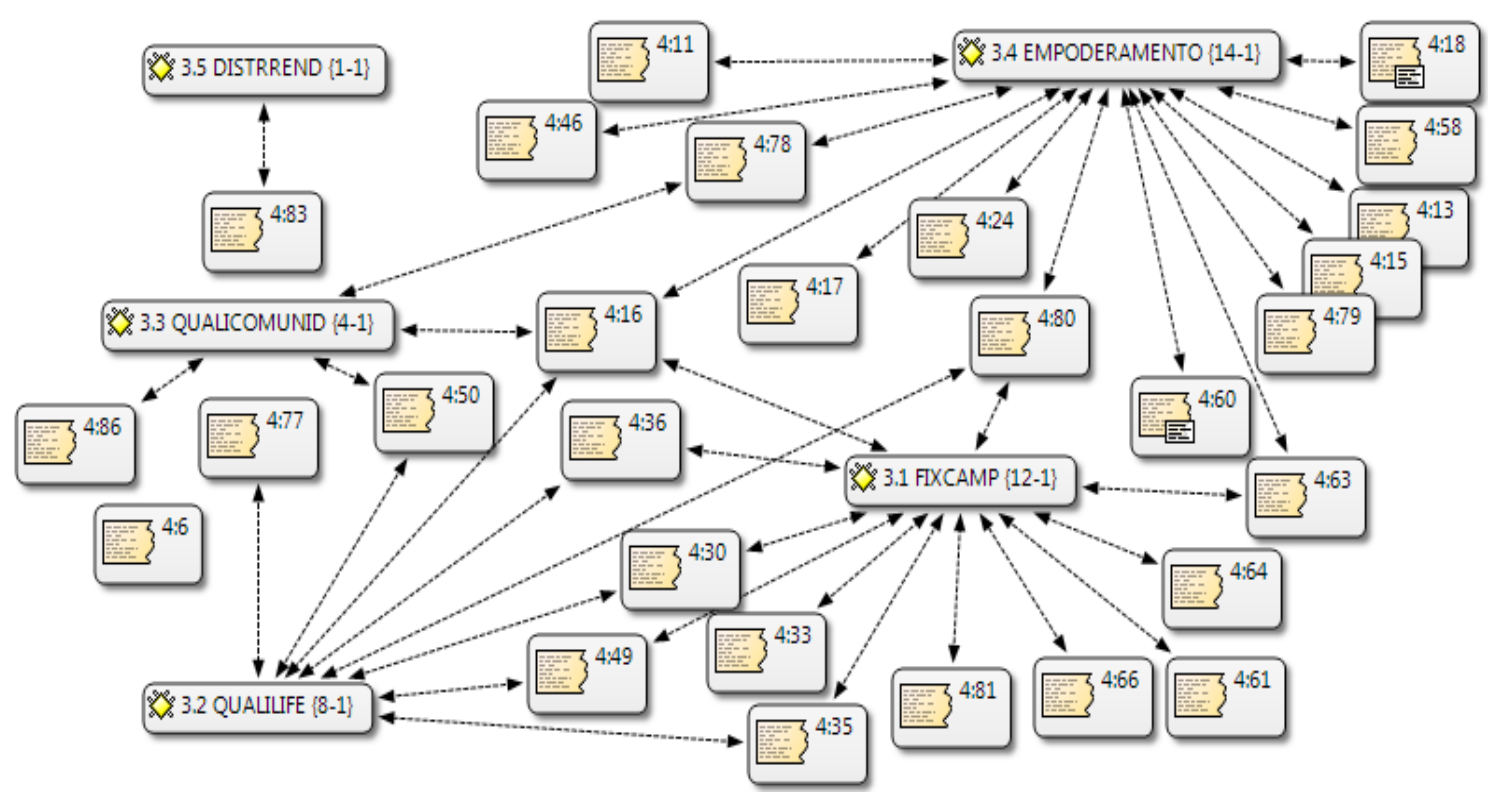

FIGURA 8 - Representação dos trechos associados à Dimensão Social.

TABELA 6 - Categoria da dimensão social.

- Modelo de gestão participativo, estimulando o exercício da cidadania;

- Financiamento da produção com a paga na forma de produção;

- Disponibilização de estrutura para que os produtores possam realizar as suas reuniões e a disponibilização de alojamentos utilizados pelos produtores durante os eventos da associação;

- Realização de reuniões com a participação obrigatória de todos para trocar ideias, acompanhar a produção, o andamento das atividades do projeto, discutir demandas do grupo e buscar formas de supri-las;

- Capacitação dos associados tecnicamente para gerenciar a sua unidade produtiva e para participar da associação;

- Definição de grupos de acordo com a proximidade das propriedades dos associados;

- Existência de diferenças entre os grupos no que diz respeito à interação dos membros, o comprometimento com o projeto impactando no desenvolvimento econômico e social do grupo. Isto é evidenciado pela diferença de renda apontada no relatório;

- Investimento na formação dos filhos dos proprietários como técnicos, possibilitando a aplicação dos conhecimentos em suas propriedades;

- Apoio técnico direcionado individualmente para cada grupo;

- Compra da produção dos associados;

- Beneficiamento da produção do associado;

- Utilização de mão de obra feminina;

- Disponibilidade de postos de trabalho na agroindústria e nas propriedades;

- Solidariedade entre os associados;

- Geração de sustento para as famílias dos associados e, de forma indireta, criação de renda para a comunidade com o aquecimento do comércio local;

- Desenvolvimento de cultura conservacionista;

- Apoio da associação para contornar os problemas apresentados pelos grupos;

- Compromisso formal com a fixação das famílias no campo com a organização das famílias em grupos de estudo, trabalho e ajuda mútua;

- Melhoria de renda dos associados com a implantação do projeto;

- Processo de gestão participativo nos papéis de coordenador, líder e representante mulher;

- Verificação do sentimento de apropriação do projeto. 
$\mathrm{Na}$ dimensão social, foram verificados obstáculos ao crescimento do projeto. Isso decorre também devido questões culturais conforme foram citadas pelos entrevistados, como apresentado no seguinte trecho:

Segundo algumas pessoas, a cultura também influencia nessa dinâmica dos grupos. Embora alguns grupos já tenham sido formados em um ambiente familiar marcado pela união e ajuda mútua, a presença de interesses pessoais acima dos objetivos coletivos é marcante.

\subsection{Dimensões subjacentes}

O trabalho teve como objetivo a avaliação da dimensão da sustentabilidade a partir do modelo do triple bottom line. No entanto, a literatura aponta para a interface destas dimensões com outras dimensões mais específicas, como: política, institucional, cultural, democrática, ética, tecnológica, entre outras (Moura, 2002).

De fato, da análise do relatório outras dimensões emergem e que impactam diretamente no projeto. A dimensão institucional emergiu de forma bastante positiva, contribuindo com o projeto. Esta dimensão pode ser verificada na forma organizacional do projeto, no sistema de gestão, em seus procedimentos, no seu estatuto, nos seguintes trechos.

Como alternativa de solução para esse problema, em 2006 foi criada a Cooperativa Agroflorestal do Projeto RECA - COOPER RECA. Essa nova instância da organização ficaria então responsável pelas atividades de comercialização dos produtos RECA, tendo estatuto e regimento próprios. Foi estruturado um novo modelo organizacional, onde uma mesma organização social congrega em sua estrutura uma associação e uma cooperativa.

$\cdots$

Para conquistar novos mercados, mais exigentes a cada dia, deve-se adequar a uma série de padrões, que vão desde o manejo dos cultivos, QUESTÕES BUROCRÁ-
TICAS, e até o processo produtivo, como o controle de qualidade, a higiene e a segurança do trabalho, adequação da estrutura física das agroindústrias, entre diversos outros pontos...

Pode-se perceber que já existe uma preocupação em preparar-se para o crescimento. Foi realizado em 2008 o planejamento estratégico do RECA, onde os associados e os principais parceiros do projeto reuniram-se para discutir e planejar a atuação do RECA até 2016.

A dimensão política contribui negativamente. Percebe-se, pela análise do relatório, a ausência de políticas públicas governamentais estaduais atribuídas a esta dimensão. Tal inferência é feita a partir dos seguintes trechos:

Tendo em vista esse conflito, pode-se notar uma grande desaprovação por parte dos moradores de Nova Califórnia em relação ao Governo do Estado de Rondônia e, pelo mesmo motivo de descaso, à Prefeitura de Porto Velho, município do qual faz parte, apesar dos $360 \mathrm{~km}$ de distância da cidade. Em contrapartida, o Governo Federal exerce uma boa atuação de apoio ao RECA e a outras organizações locais por meio de órgãos como Embrapa (Empresa Brasileira de Pesquisa Agropecuária), Emater (Empresa de Assistência Técnica e Extensão Rural), MDA (Ministério de Desenvolvimento Agrário) e Conab (Companhia Nacional de Abastecimento). A parceria nesses casos é geralmente de assessoria, cursos de capacitação ou palestras.

O distrito de Nova Califórnia se encontra a $360 \mathrm{~km}$ de Porto Velho... O percurso é marcado pela ruim condição da estrada.

Apesar das dificuldades referentes ao transporte individual, o que mais atrapalha a vida dos moradores locais e do projeto RECA são as condições dos ramais e do deslocamento de cargas. Nova Califórnia é dividida entre a vila e os ramais, que são pequenas estradas de barro pelas quais a população tem acesso aos sítios e chácaras. Os ramais foram traçados há décadas e, desde então, a população exige que sejam feitas obras para regularização e manutenção dos mesmos. Os moradores contam que, nos meses de chuva, os ramais alagam, "o solo da Amazônia quando se mistura com água atola 
até cavalo", contam. Sem respostas da prefeitura, vários grupos se organizam em mutirões que arrumam os ramais para não perderem parte da produção por falta de escoamento dos produtos.

O aspecto cultural voltado para a conservação ambiental foi importante para a formação do projeto RECA. Outro aspecto que se observa na nota de campo é que as dificuldades iniciais foram importantes para a união dos grupos e a manutenção da cultura conservacionista.

A região da Ponta do Abunã é formada por famílias de toda parte do Brasil, desde migrantes atraídos pela era da borracha ou pela divisão de terras feita pelo Incra na década de 70, até moradores antigos na região e indígenas. Cada um trouxe consigo seus hábitos e costumes. ...

A maioria dos colonos encontraram[ou] na região as mesmas dificuldades e passaram[ou] a lutar pelos mesmos direitos.

...

Ao tratar sobre cultura regional vinculada ao projeto RECA não se pode deixar de citar alguns pontos: a valorização da floresta, a soberania alimentar e a ampliação da cidadania.A consciência da necessidade de se conservar a vegetação local foi passada para os colonos que lá chegaram pelos moradores da região, principalmente devido à filosofia do seringueiro que sobrevive da floresta, sem em nenhum momento desmatá-la.

Hoje em dia, depois de anos de aprendizagem e convivência, a conservação da floresta é algo inerente à cultura local, é um valor passado dos mais experientes aos mais novos por meio de histórias, conversas e, principalmente, pelo exemplo.

\section{Conclusão}

O trabalho teve como objetivo a verificação da contribuição do Projeto de Reflorestamento Consorciado e Adensado - RECA, dentro da proposta da contribuição do sistema agroflorestal para a sustentabilidade considerando o modelo triple bottom line.
A partir da análise de conteúdo da nota de campo, o projeto foi analisado considerando as dimensões econômica, ambiental e social. Como técnica para a análise, trabalhou-se com categorias que emergiram do referencial teórico apresentado. O RECA pode ser considerado um sistema agrossilvicultural totalmente inserido dentro da cultura da região em que foi implantado, podendo ser caracterizado, também, como um sistema agroflorestal. A teoria já considera que o sistema agroflorestal tem relação com os pilares da sustentabilidade que necessitam de um baixo capital para sua manutenção (Raintree \& Warner, 1986).

Ficou evidenciado que o projeto RECA tem uma contribuição importante para a sustentabilidade. Isto se verifica principalmente pela prática adotada pelos associados do projeto que utilizam a floresta como fonte geradora de renda consorciando cultivos agrossilvícolas como a pupunha, o cupuaçu e a castanha-do-Brasil em um sistema agroflorestal, refletindo na melhoria da qualidade de vida dos agricultores.

Como o projeto é dividido em grupos de associados, formados a partir da proximidade geográfica dos agricultores, existem diferenças de performance entre estes grupos. Tais grupos devem seguir os objetivos estabelecidos no estatuto da Associação e que foram constatados nas práticas observadas no projeto.

A orientação dos agricultores, a implantação de um sistema educacional adequado à realidade rural, a compra dos produtos dos associados, a implantação da agroindústria, a busca de alternativas para ajudar na conservação e na preservação do meio ambiente e da biodiversidade local, são práticas que foram identificadas no projeto e por associados na pesquisa como práticas de sustentabilidade. 
Os efeitos do RECA mais perceptíveis são, provavelmente, os relativos à melhoria de renda dos associados. Anteriormente à formação das associações locais, os produtores tentavam sustentar suas famílias individualmente, sem qualquer apoio ou instrução. Conforme as associações foram amadurecendo, e principalmente com o início do projeto RECA, os produtores foram aprendendo a se articular coletivamente e logo conseguiram colocar em prática as ideias de florestas produtivas. Esta capacidade de articulação foi relacionada no estudo dentro do conceito de empoderamento em Paulo Freire apud De Castro Valoura (2010), que considera como empoderada a pessoa ou grupo

\section{Referências}

Almeida, C. M. V. C. de; Müller, M. W.; Sena-Gomes, A. R.; Matos, P. G. G. Pesquisa em Sistemas Agroflorestais e Agricultura Sustentável: Manejo do Sistema. In: Anais do Workshop Latino-Americano sobre Pesquisa de Cacau, Ilhéus, Bahia, 22 - 24 de outubro de 2002. Anais com resumo expandido (CD-ROM).

Almeida, J. R. de. Gestão ambiental para o desenvolvimento sustentável. Rio de Janeiro: Thex, 2010.

Anderson, A. B.; Gely, A.; Strudwich, J.; Sobel, G. L.; Pinto, M. Um sistema agroflorestal na várzea do estuário amazônico. Acta Amazônica, 15(1-2), 195-224, 1985.

Antunes, M. O caminho do empoderamento: articulando as noções de desenvolvimento, pobreza e empoderamento. In: Antunes, M.; Romano, J. O. Empoderamento e direitos no combate à pobreza. Rio de Janeiro: ActionAid Brasil, 2002.

Araújo, A. R.; Leite, L. F. C.; Oliveira Júnior, J. O. L.; Sagrilo, E.; Araújo, F. S.; Lopes, A. N. C. Propriedades químicas de um Argissolo Vermelho Amarelo sob sistemas de rotação e sucessão de culturas e floresta nativa de Cerrados. In: Anais do $30^{\circ}$ Congresso Brasileiro de Ciência do Solo, Recife, 2005. Recife: SBCS, 2005. 1 CD-ROM.

Baquero, V. Â. R. Empoderamento: instrumento de emancipação social? Uma discussão conceitual. Revista Debates, 6(1), 173-187, 2012. que realiza por si mesma as mudanças e ações que a levam a evoluir e fortalecer, condição que no estudo foi atribuída a uma dimensão social da sustentabilidade.

Observou-se, por meio das evidências das notas de campo, que o projeto RECA contribui com as dimensões da sustentabilidade, bem como há indícios fortes de dimensões adicionais que podem ser atribuídas ao projeto. Isto nos permite sugerir a realização de estudos adicionais com o fim de verificar a contribuição de dimensões políticas, culturais e institucionais para a sustentabilidade e continuidade de um projeto agroflorestal.

Barbieri, J. C.; Cajazeira, J. E. R. Responsabilidade social empresarial e empresa sustentável. São Paulo: Saraiva, 2009.

Bardin, L. Análise de conteúdo. Trad. de A. Rego e A. Pinheiro. Lisboa: Edições 70, 2006.

Bellen, H. M. V. Indicadores de sustentabilidade. 2. ed. Rio de Janeiro: FGV, 2006.

Bogdan, R.; Biklen, S. Investigação qualitativa em educação. Uma introdução à teoria e aos métodos. Porto: Porto Editora, 1994.

Castro, A. P. de; Fraxe, T. de J. P.; Santiago, J. L.; Matos, R. B.; Pinto, I. C. Os sistemas agroflorestais como alternativa de sustentabilidade em ecossistemas de várzea no Amazonas. Acta Amazonica, 39(2), 279-288, 2009.

Chiesa, V.; Manzini, R.; Noci, G. Towards a sustainable view of the competitive system. Long Range Planning, 32(5), 519-530, 1999.

Coelho Junior, L. M.; de Rezende, J. L. P.; de Oliveira, A. D.; Coimbra, L. A. B.; de Souza, Á. N. Análise de investimento de um sistema agroflorestal sob situação de risco. Cerne, 14(4), 368-378, 2008.

Comissão Mundial sobre Meio Ambiente e Desenvolvimento. Nosso futuro comum: Brundtland, Gro Harlem. 2. ed. Rio de Janeiro: Fundação Getúlio Vargas, 1991. 
Dantas, M. Aspectos ambientais de sistemas agroflorestais. In: Anais do I Congresso Brasileiro sobre Sistemas Agroflorestais. Porto Velho-RO, 3-7 julho/1994. p. 433-453.

De Castro Valoura, L. Paulo Freire, o educador brasileiro autor do termo Empoderamento, em seu sentido transformador. 2010. Disponível em: <http://tupi.fisica.ufmg.br/ michel/docs/Artigos_e_textos/Comportamento_organizacional/empowerment_por_paulo_freire.pdf $>$.

Deponti, C. M. Indicadores para avaliação da sustentabilidade em contextos de desenvolvimento rural local. $153 \mathrm{f}$. Monografia (Programa de Pós-Graduação em Desenvolvimento Rural) - Universidade Federal do Rio Grande do Sul, 2001. Disponível em: <http://www.emater.tche.br/site/ arquivos_pdf/teses/mono_Cidonea_Machado.pdf $>$. Acesso em: 18 jun. 2012.

De Souza-Minayo, M. C. Ciência, técnica e arte: o desafio da pesquisa social. Pesquisa social: teoria, método e criatividade. 17. ed., v. 23. Petrópolis: Vozes, 1994. p. 9-29.

Elkington, J. Canibais com garfo e faca. São Paulo: Makron Books, 2001.

EMBRAPA - Empresa Brasileira de Pesquisa Agropecuária Embrapa Meio-Norte. Ministério da Agricultura, Pecuária e Abastecimento. Estratégias de Desenvolvimento Rural e Alternativas Tecnológicas para a Agricultura Familiar na Região Meio-Norte. In: Oliveira, F. C.; Leite, L. F. C.; Lima, S. S. de; Oliveira Júnior, J. O. L. de. Estratégias de desenvolvimento rural e alternativas tecnológicas para a agricultura familiar na região Meio-Norte. Piauí: Embrapa, 2008. p 119-144.

EMBRAPA - Empresa Brasileira de Pesquisa Agropecuária. Ministério da Agricultura, Pecuária e Abastecimento. Prosa Rural - Sistemas agroflorestais para o semiárido. Ceará, 2006. Disponível em: $<$ https://www.embrapa.br/tema-integracao-lavoura-pecuaria-floresta-ilpf/busca-de-noticias/-/ noticia/2551732/prosa-rural---sistemas-agroflorestais-para-o-semi-arido>. Acesso em: 14 mar. 2016.

Fernandes, E. C. M.; Serrão, E. A. S. Protótipo e modelos agrossilvipastoris sustentáveis. In: Anais do Seminário Internacional sobre Meio Ambiente, Pobreza e Desenvolvimento da Amazônia. Belém, PA: PRODEBA, 1992. p. 245-251.

Flick, U. Introdução à pesquisa qualitativa. Trad. Joice Elias Costa. 3. ed. Porto Alegre: Artmed, 2009. 405 p.
Freire, P.; Shor, I. Medo e ousadia: o cotidiano do professor. Rio de Janeiro: Paz e Terra, 1986.

Godoy, A. S. A pesquisa qualitativa e sua utilização em administração de empresas. Revista de Administração de Empresas, 35(4), 65-71, 1995.

IBGE - Instituto Brasileiro de Geografia e Estatística. Indicadores de Desenvolvimento Sustentável: Brasil 2004. Disponível em: $<$ http://www.ibge.gov.br/home/geociencias/ recursosnaturais/ids/introducao.pdf $>$. Acesso em: 26 maio 2013.

Kato, O. R.; Shimizu, M. K.; Borges, A. C. M. R., Azevedo, C. M. B. C.; Oliveira, J. S. R.; Vasconcelos, S. S.; Sá, T. D. de A. Desenvolvimento da produção de frutas em sistemas agroflorestais no estado do Pará. In: XXII Congresso Brasileiro de Fruticultura. Bento Gonçalves, Rio Grande do Sul, 2012.

Lee, K.; Kim, J. Current status of CSR in the realm of supply management: the case of the Korean electronics industry. Supply Chain Management: An International Journal, 14(2), 138-148, 2009.

Lovelock, J. Environment in crisis: We are past the point of no return. The Independent, London, 16/01/2006. Disponível em: <http://news.independent.co.uk/environment/ article338878.ece>.

Lozano, R. Envisioning sustainability three-dimensionally. Journal of Cleaner Production, 16(17), 1838-1846, 2008.

Lundgren, B. O.; Raintree, J. B. Sustained Agroforestry. In: Nestel, B. Agricultural Research for Development: potentials and challenges in Asia. ISNAR: The Hague, 1982. p. 37-49.

Machado, J. A. C.; Fenzl, N. A sustentabilidade do desenvolvimento e a demanda material da economia: o caso do Brasil comparado ao de países industrializados. 2001. Disponível em: <www.ufpa.br/amazonia21/publicacoes/ MFA-Brasil/Artigo-tese-Machado-MFA-Brasil.htm>. Acesso em: 20 dez. 2012.

Maddison, A. World Development and Outlook 1820-2030: Its Implications for Energy Use. London, 20th February 2005. Disponível em: $<$ http://www.ggdc.net/maddison>.

Martins, C. H. B.; Oliveira, N. Indicadores de qualidade de vida e de qualidade ambiental: a necessidade de integração das dimensões social, econômica e ambiental. Indicadores econômico-ambientais na perspectiva da sustentabilidade. Porto Alegre: FEE, 2005. 
Meadows, D. H.; Meadows, D. I.; Randers, J.; Behrens, W. W. I. The Limits to Growth: Report for the Club of Rome's Project on Predicament of Mankind. New York: New American Library, 1972.

Merriam, S. B. Qualitative Research and Case Study Applications in Education. San Francisco: Jossey-Bass Inc. Publishers, 1998. p. 1-25.

Moura, L. G. V. Indicadores para avaliação da sustentabilidade em sistemas de produção da agricultura familiar: o caso dos fumicultores de Agudos-RS. 2002. 213 f. Porto Alegre, Dissertação (Programa de Pós-Graduação em Desenvolvimento Rural) - Universidade Federal do Rio Grande do Sul, 2002. Disponível em: <http://www.lume. ufrgs.br/handle/10183/2624>. Acesso em: 22 jun. 2012.

Nair, P. K. R. Agroforestry in the tropics. London: Kluwer Academic Publisher, 1990. 664 p.

Nobre Filho, W.; Simantob, M.; Barbieri, J. Em busca da sustentabilidade socioambiental: o caso Copesul. Anais do $9^{\circ}$ Simpósio de Administração da Produção, Logística e Operações Internacionais - SIMPOI FGV-EAESP, 2006.
Oliveira, F. C.; Leite, L. F. C.; Lima, S. S. de; Oliveira Júnior, J. O. L. de. Estratégias de desenvolvimento rural e alternativas tecnológicas para a agricultura familiar na região Meio-Norte. Piauí: Embrapa, 2008.

Peneireiro, F. Formação dos agentes socioambientais no Xingu: valorizando as descobertas e iniciativas agroflorestais. São Paulo: Instituto Socioambiental, 2007.

Perkins, D. D.; Zimmerman, M. A. Empowerment meets narrative: listening to stories and creating settings. American Journal of Community Psicology, 23(5), 569-579, 1995.

Raintree, J.; Warner, R. Agroforestry pathways for the intensification of shifting cultivation. Agroforestry Systems, 4, 39-54, 1986.

Rogers, P.; Jalal, K.; Boyd, J. An introduction to sustainable development. Londres: Earthscan, 2008. 416 p.

Sachs, I. Caminhos para o desenvolvimento sustentável. Rio de Janeiro: Garamond, 2009.

Yin, R. Case Study Research: Design and Methods. 2. ed. Thousand Oaks, CA: SAGE Publications. 1994. 